\title{
MACHADO DE ASSIS, GUIMARÃES ROSA E O ESPELHO
}

Márcio Vinícius do Rosário Hilário

Professor do Colégio Pedro II. Doutor em Literatura Brasileira pela UFRJ.

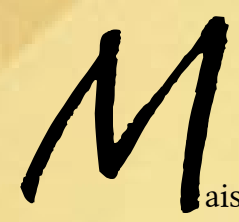

Resumo

ais do que meros contadores de histórias ou estórias, os grandes escritores são capazes de criar universos ficcionais particulares, nos quais as mínimas partes se inter-relacionam dentro de um todo poético articulado. Nesse sentido, todos os elementos constituintes de um enredo combinamse organicamente de tal modo que, por meio de cada um é possível ver representado o discurso maior pretendido pelo autor, embora somente na complementaridade de um com o outro se possa realmente materializar a totalidade do tecido. Em outras palavras, quando um escritor elabora seu texto, ele está ao mesmo tempo criando um universo particular - porque tudo naquela tessitura se combina de forma muito específica - e geral - na medida em que existe um princípio regente o qual se manifestará em qualquer outro texto produzido por ele. Fosse diferente, bastaria ao escritor (e ao leitor) apenas um único objeto artístico, já que qualquer outro diria exatamente aquilo que um primeiro já teria revelado. Por extensão, do mesmo modo que um conto pode interagir com toda a ficção narrativa que compõe a obra de um artista, dentro dele todas as suas partes estão conectadas numa espécie de jogo metonímico. Partindo, então, da premissa de que todo texto literário é merecedor de uma leitura singularizante, ainda que ele, obviamente, se insira no todo de um projeto estético, optamos por trabalhar em contos homônimos - "O espelho" - de Machado de Assis e de Guimarães Rosa - seus aspectos imagético-simbólicos, dando um destaque especial, sobretudo, para o objeto-tema escolhido por seus autores.

Palavras-chave: Machado de Assis. Guimarães Rosa. Espelho. Símbolo. Intertextualidade. 
Quase sempre, quando nos referimos aos grandes escritores que imortalizaram obras na literatura universal, corremos o risco de sermos redundantes ou de cairmos em lugar comum. Geniais, únicos, incomparáveis. É assim que, muitas vezes, repetimos automaticamente, enquanto, por outro lado, em nossa prática cotidiana - principalmente para aqueles que lidam com a sala de aula - fazemos exatamente o oposto: matamos a genial singularidade em nome da defesa de visões esquemáticas arcaicas, mas que ainda se perpetuam em nossos estudos literários. Na experiência da Educação Básica, o cenário é ainda pior, visto que a maior parte das avaliações ainda parecem consagrar a chave diacrônica dos chamados estilos de época. Como resultado, além de pouco se desenvolver de fato o gosto pela leitura dos textos literários - principalmente os clássicos - essa práxis ainda impede que a mensagem desejada pelos escritores continue viva e em plena comunicação com novos leitores. Com isso, muito embora seus nomes sejam bastante conhecidos, celebrados e aclamados, seus textos permanecem mudos e desconhecidos da maior parte do público. As análises críticas, quando se interpõem dessa maneira entre o leitor e o texto, fazem mais o desserviço de silenciar o discurso do escritor do que o potencializar. É preciso, então, considerar de imediato dois aspectos importantes para a delimitação dessa abordagem: (a) os estudiosos de literatura devem objetivar cada vez mais a um trabalho para a comunicabilidade dos textos literários, a fim de que eles possam seguir como mensagem e não como exemplificações de características pré-definidas de técnicas e de estilos; (b) é preciso rever o modo como se trabalha a literatura, enquanto disciplina escolar, almejando mais a formação do leitor crítico e menos a preparação pragmática e vazia de significações.

Feito esse enquadramento inicial, o primeiro passo que daremos na direção da análise dos textos de Machado de Assis e de Guimarães Rosa é tentar, justamente, centrar nosso foco naquilo que eles oferecem como contribuições individuais e, a partir daí, demonstrar como logicamente eles refletem e ajudam a construir os projetos estéticos desses escritores. Para tanto, é preciso igualmente defender que, muito embora esteja inserido numa articulação orgânica com o todo da obra enquanto parte, o texto não pode ser visto apenas como mais do mesmo ou como pretexto para provar uma verdade previamente concebida. Seus elementos constituintes foram unicamente elaborados para compor aquele específico universo linguístico e imagético de representação e, por isso mesmo, só 
nele e a partir dele podem ser analisados.

A defesa de que o texto literário deve ser tratado a partir desses seus elementos mais singulares não impede que o intérprete traga algumas luzes externas para efetuar a leitura do texto a fim de demonstrar a amplitude de seu alcance. O que não se pode permitir é que, sob essa égide, o discurso do crítico acabe por suplantar aquele que deveria estar em evidência: o discurso do texto em si. Em outras palavras, concordando com Ronaldes de Melo e Souza (1978),

o texto literário possui um sentido específico, que independe da figura realística do emissor, ao mesmo tempo que transmite todas as alegorias possíveis que o receptor lhe queira atribuir. Em síntese, o que o texto diz é o seu sentido (SOUZA, 1978, p. 15).

Ao analisar por esse prisma, o crítico demonstra sua preocupação legítima com a tendência dominante de que os estudos literários acabam por basearem-se exclusivamente em outros discursos de saber como se deles fosse seu fiel depositário.

\footnotetext{
Não é outra a violência que se pratica contra a obra literária, senão esta: a de subordiná-la a uma pergunta formulada exclusivamente pelo crítico, a serviço da ideologia tal ou qual. Ora, bem sabemos que a resposta é uma função da pergunta. Se se faz uma pergunta psicológica, a obra se nos revela psicologicamente; se se faz uma pergunta sociológica, a obra se nos revela sociologicamente, e assim por diante. (SOUZA, 1978, p. 17)
}

É importante observar que em nenhum momento se está defendendo a ideia de que da obra de arte literária não se possa extrair vário e farto material para a análise de outros discursos de saber que não a própria literatura. Ou seja, é absolutamente legítimo - e diria até necessário - que historiadores, filósofos, sociólogos, psicólogos e todos os demais pesquisadores nele interessados façam uso do texto literário como objeto de estudo. No entanto, não se pode negar o fato de que, em sua essência e motivo, tais textos foram concebidos artisticamente para serem literários e que os recursos expressivos da linguagem que o definem como tal não podem ser ignorados em detrimento do conteúdo denotativo da mensagem. Cabe ao estudioso de literatura, portanto, identificar na especificidade do seu discurso de saber o seu objeto de análise, ao invés de nublá-lo com qualquer outro. Portanto, parece-nos um 
tremendo equívoco que ainda se pratiquem hegemonicamente aulas de historiografia literária, para as quais o único objetivo parece ser o treinamento para a memorização de nomes, datas e características formais genéricas sem que de fato se analise ou minimamente que se leia com gosto um único texto de literatura.

Partindo, então, da premissa de que um texto literário merece uma leitura singularizante, ainda que ele, obviamente, esteja inserido no todo de um projeto estético, optamos por trabalhar os contos de Machado de Assis e Guimarães Rosa observando seus aspectos imagético-simbólicos, sobretudo com destaque especial para o objeto-tema escolhido por seus autores: o espelho. Para tanto, é preciso vê-lo não apenas como um elemento constituinte do cenário em que se desenvolve a trama, mas como um princípio metafórico-metonímico que traduz uma poética, que, por sua vez, enquanto parte, articulase ao todo da obra do escritor.

\begin{abstract}
O espelho não tem como única função refletir uma imagem; tornando-se a alma do espelho perfeito, ela participa da imagem e, através dessa participação, passa por uma transformação. Existe, portanto, uma configuração entre o sujeito contemplado e o espelho que o contempla. A alma termina por participar da própria beleza à qual ela se abre. (CHEVALIER \& GHEERBRANT, 1999, p.396.)
\end{abstract}

Em 2008, por ocasião das comemorações do centenário da morte de Machado de Assis, apresentamos na Universidade Federal do Rio de Janeiro (UFRJ) a comunicação "Reflexões e divagações diante de 'O espelho'”, a qual mais tarde foi publicada (HILÁRIO, 2009). Nela, expusemos de que modo a ambivalência do espelho - que tanto devolve a realidade nele projetada, quanto cria a ilusão de que existe um mundo paralelo que se inicia a partir dele - simboliza o posicionamento da obra machadiana no contexto da produção literária do séc. XIX. Para a crítica tradicional, existiram dois "Machados" que cronologicamente se opuseram - um romântico, que escreveu até o final dos anos de 1870, e outro realista, que seguiu produzindo a partir dos anos de 1880. Para os críticos que rejeitam esse diagnóstico da bipolaridade do eu machadiano - dentre os quais nos inserimos ${ }^{1}$-, existe um princípio fundamental que diferencia a estética machadiana daquela praticada por qualquer outro escritor da literatura universal, e todo texto seu, em sua singularidade, compõe conjunto 
geral de sua estética. As opiniões dos críticos são divergentes, mas a do autor parece tender mais para um dos lados, visto que, desde 1858 - e, portanto, bem antes da fama -, ele já se colocava à margem dessas classificações esquemáticas: "Não somos nem espiritualista puro nem materialista; harmonizamos as doutrinas de ambas as escolas e seguimos assim em ecletismo com o qual nos damos às mil maravilhas." (ASSIS, 1965, p. 62)

Sendo assim, passemos a observar como o escritor "harmonizou as doutrinas dessas escolas" em "O espelho". Já no primeiro parágrafo, pode-se ter uma degustação, por meio da simples descrição do cenário onde se passaram parte dos acontecimentos narrados. Ali, o autor dá mostras desse tal "ecletismo" anunciado por ele mais de vinte anos antes da publicação de Papéis avulsos: "A casa ficava no morro de Santa Teresa (...). Entre a cidade, com suas agitações e aventuras, e o céu, em que as estrelas pestanejavam, através de uma atmosfera límpida e sossegada" (ASSIS, 1989, p. 153). Na escolha dos lugares, dos vocábulos e das imagens notam-se as oposições: entre descrição objetiva da vida citadina e a visão lírica do céu, posiciona-se o entrelugar perfeito para esboçar uma nova e ambivalente teoria da alma humana, visto, que, por ser morro, Santa Teresa está acima de um e abaixo do outro. Dentro dessa lógica imagética da entreposição - tal qual a lâmina de vidro do espelho, que é o ponto médio entre o objeto e a imagem, a realidade e a ilusão -, a obra machadiana posiciona-se de modo a representar mais intensamente a dualidade do mundo narrado. Aliás, é justamente essa concepção dual de realidade que percorre todo o conto, que, inclusive, conta com dois narradores: o primeiro deles, posicionado em $3^{\text {a }}$ pessoa, apresenta os personagens e o ambiente, e introduz a questão para que Jacobina, tirado do seu silêncio, possa expor pessoalmente sua teoria para seus amigos - "investigadores de cousas metafísicas" (ASSIS, 1989, p. 153), que resolviam "amigavelmente os mais árduos problemas do universo" (ASSIS, 1989, p. 153). A partir do momento em que é alçado à posição de personagem-narrador, Jacobina impõe o silêncio aos seus ouvintes - condição fundamental para a exposição de sua complexa teoria: "Espantem-se à vontade; podem ficar de boca aberta, dar de ombros, tudo; não admito réplica. Se me replicarem, acabo o charuto e vou dormir" (ASSIS, 1989, p. 154). Não seria difícil supor que, diante dessa imposição, o narrador estaria livre para apresentar seu monólogo, quebrando assim a perspectiva dual da narrativa. Não é o que ocorre. A teoria apresentada fundamenta-se num princípio eminentemente dialógico, a partir da revelação de que 
em cada ser humano coexistem pelo menos duas almas - uma, interior, que olha de dentro para fora; e outra, exterior, que olha de fora para dentro. A alma exterior, por sua vez, "muda de natureza e de estado" (ASSIS, 1989, p. 155), por isso, varia conforme o indivíduo ou o momento, podendo ser, assim, "um espírito, um fluido, um homem, muitos homens, um objeto, uma operação" (ASSIS, 1989, p. 154). E ainda no contexto da composição dual da linguagem, refletindo uma perspectiva dúbia de realidade, o conto também utiliza como recurso formal a justaposição de palavras de registros distintos, exemplificado na definição segundo a qual "o homem é metafisicamente falando uma laranja” (ASSIS, 1989, p. 154).

O exemplo mais concreto para apresentar a teria de Jacobina é, contudo, a narração de um episódio que aconteceu com ele mesmo. Tendo nascido e crescido na pobreza, tornara-se aos vinte e cinco anos alferes da guarda nacional, para despeito de alguns e orgulho de muitos outros, segundo o que disse: "e a prova disso é que todo o fardamento me foi dado por amigos" (ASSIS, 1989, p. 156). Quando tia Marcolina, viúva do capitão Peçanha, "pediu que fosse ter com ela e levasse a farda" (ASSIS, 1989, p. 156), o jovem não esperava que fosse recebido com tantas cortesias e rapapés por todos da casa, os quais passaram a tratar-lhe por "senhor alferes". Menos ainda imaginaria que sua estada se prolongaria por mais de um mês. Continua sua exposição dizendo que "Na mesa, tinha (...) o melhor lugar, e era o primeiro servido" (ASSIS, 1989, p. 156) e para dar uma noção mais concreta de como estava sendo paparicado por conta de sua nova função social, personagem-narrador chega a afirmar o seguinte para seus ouvintes:

Não imaginam. Se lhes disser que o entusiasmo de tia Marcolina chegou ao ponto de mandar por no meu quarto, um grande espelho, obra rica e magnífica, que destoava do resto da casa, cuja mobília era modesta e simples... Era um espelho que lhe dera a madrinha, e que esta herdara da mãe, que o comprara a uma das fidalgas vindas em 1808 com a corte de D. João VI. Não sei o que havia nisso de verdade; era a tradição. (ASSIS, 1989, p. 156)

Nota-se no último período do trecho um exemplo da fina ironia machadiana que, ao mesmo tempo em que arma a cena, desarma-a no sentido de intensificar a dinâmica de um mundo no qual a aparência está permanentemente em conflito com a essência. O próprio valor histórico do objeto espelho pode ser 
nada mais do que uma invenção, assim como toda a importância que passou a ser atribuída ao jovem "senhor alferes", que tão rapidamente se acostumou com o tratamento recebido que, quando a tia foi obrigada a viajar para longe com o cunhado, às pressas, a fim de visitar uma filha que "estava mal e à morte" (ASSIS, 1989, p. 157), ele se sentiu um pouco vazio de si mesmo. O alferes havia eliminado o homem. "Durante alguns dias as duas naturezas equilibraram-se; mas não tardou que a primeira cedesse à outra" (ASSIS, 1989, p. 157), ficandolhe "uma parte mínima de humanidade. Acontece então que a alma exterior, que era dantes o sol, o ar, o campo, os olhos das moças, mudou de natureza, e passou a ser a cortesia e os rapapés da casa" (ASSIS, 1989, p. 157), tudo o que lhe falava do posto e nada do que lhe falava do homem. Por isso, seu vazio existencial se agravou ainda mais quando os escravos, aproveitando a ausência de sua senhora, "tinham resolvido fugir durante a noite; e assim o fizeram" (ASSIS, 1989, p. 158). Foi nesse momento que, diante da mais completa solidão em que se encontrava, Jacobina vivenciou o estranho fenômeno diante do espelho:

Olhei e recuei. O próprio vidro parecia conjurado com o resto do universo; não me estampou a figura nítida e inteira, mas vaga e esfumada, difusa, sombra de sombra. A realidade das leis físicas não permite negar que o espelho reproduziu-me textualmente, com os mesmos contornos e feições; assim devia ter sido. Mas tal não foi a minha sensação. (ASSIS, 1989, p. 160-161)

Também aqui se representa a dualidade com a qual se encena o conflito de caracteres do personagem-narrador. Ao confrontar a objetividade das leis físicas com a subjetividade do seu olhar, Jacobina justapõe elementos contrários numa tensão harmônica tão característica da obra machadiana. E a solução encontrada por ele também está na conciliação dessas forças opostas:

Lembrou-me vestir a farda de alferes. Vestia-a, aprontei-me de todo; e, como estava defronte do espelho, levantei os olhos, e... não lhes digo nada: o vidro reproduziu então a figura integral; nenhuma linha de menos, nenhum contorno diverso; era eu mesmo, o alferes, que achava, enfim, a alma exterior. Essa alma ausente com a dona do sítio, dispersa e fugida com os escravos, ei-la recolhida no espelho. (ASSIS, 1989, p. 161) 
Restituída a sua completude e tendo provado a sua teoria aos, até então, incrédulos amigos, o personagem-narrador sai de cena, devolvendo a palavra ao primeiro narrador, que, por sua conta, parece reconhecer Jacobina como a legítima voz do conto, visto que o termina sem avaliar ou questionar, ou mesmo sem dar a palavra final, já que poderia - se quisesse - desautorizar tudo o que foi relatado em $l^{\text {a }}$ pessoa. Não foi o que fez, narrou apenas o retorno de Jacobina ao silêncio, que agora também era o que havia sobrado aos pasmos amigos: "Quando os outros voltaram a si, o narrador tinha descido as escadas" (ASSIS, 1989, p. 162).

O diálogo intertextual que Guimarães Rosa parece buscar com Machado de Assis por meio de seu conto homônimo poderia sugerir mais afinidades que distanciamentos. No entanto, se observadas um pouco mais de perto, essas semelhanças desaparecem rapidamente, deixando claro que estamos diante de dois temperamentos estéticos completamente diferentes, que têm em comum apenas o fato de serem singularmente geniais. Tenha sido uma escolha proposital ou não, o fato é que "O espelho", de Guimarães Rosa, foi posicionado como o décimo primeiro conto das Primeiras estórias, o que ironicamente remete a um numeral em que os algarismos parecem estar espelhados entre si. Vale lembrar que, ainda no plano das possíveis coincidências, seu antecessor machadiano era o décimo conto de Papéis avulsos. Ainda assim, ao contrário da dupla mediação narrativa usada por Machado, Rosa trabalha com apenas um narrador-personagem, que verbaliza seu aparente monólogo. Dizemos aparente porque - assim como ocorre em Grande sertão: veredas - o narrador parece conversar com um interlocutor de voz inaudita no texto, que, mesmo sendo alguém "que sabe e estuda" (ROSA, 1969, p. 71), recebe dele um convite apenas para ouvi-lo e acompanhálo em seu novo percurso narrativo:

-Se quer seguir-me, narro-lhe; não uma aventura, mas experiência, a que me induziram, alternadamente, séries de raciocínios e intuições. Tomou-me tempo, desânimos, porém, um tanto à-parte de todos, penetrando conhecimento que outros ainda ignoram (ROSA, 1969, p. 71).

Ao negar a representação convencional de uma trama de ações, muitas vezes baseada apenas na causalidade de acontecimentos, e seguir na direção de um mergulho que deseja explorar mais profundamente as questões da existência, os narradores 
machadiano e rosiano se aproximam em atitude. Ou seja, também optando por contar não necessariamente as ações da trama, mas as reflexões do drama, o narrador de Rosa apresentou sua espécie de teoria da alma humana, reportandose "ao transcendente" para tratar de "de fenômenos sutis" (ROSA, 1969, p. 71). Entretanto, o narrador desse conto de Primeiras estórias não deseja provar a existência de uma alma exterior mutável e mutante. Nisso ele já a reconhece, mas não se conforma com ela. Seu desejo, de fato, é poder contemplar a face da alma interior. Jacobina se surpreendera ao não se ver refletido diante do espelho quando lhe faltou a alma exterior, o narrador anônimo de Guimarães Rosa espanta-se quando se vê mas não se reconhece:

E o que enxerguei, por instante, foi uma figura, perfil humano, desagradável ao derradeiro grau, repulsivo senão hediondo. Deu-me náusea, aquele homem, causava-me ódio e susto, eriçamento, espavor. E era logo descobri... era eu mesmo! (ROSA, 1969, p. 73).

Em Machado, a imagem objetivamente projetada no espelho segundo os princípios físicos não interessava ao personagemnarrador, porque, completamente vazio de si mesmo, só aceitava como verdadeira a figura do eu-alferes - a alma exterior passou a preencher a totalidade da sua existência vazia. Em Rosa, mesmo essa própria imagem diretamente refletida, a que Jacobina não conseguia mais enxergar, representaria uma falsa visão do indivíduo, que, ao duvidar de que a verdade do seu eu possa ser mostrada a partir do que se vê no espelho, começa a querer mergulhar cada vez mais na busca do seu eu verdadeiro. Machado de Assis estaria, na encenação do drama de Jacobina, colocando em xeque a lógica de uma sociedade de aparências. Já Guimarães Rosa coloca seu narrador no meio do redemoinho para buscar o sentido do existir.

Quem se olha no espelho, o faz partindo de um preceito afetivo, de um mais ou menos falaz pressuposto: ninguém se acha na verdade feio: quando muito, em certos momentos, desgostamo-nos por provisoriamente discrepantes de um ideal estético já aceito. Sou claro? O que se busca, então, é verificar, acertar, trabalhar, um modelo subjetivo, preexistente; enfim, ampliar o ilusório, mediante sucessivas novas capas de ilusão. $\mathrm{Eu}$, porém, era um perquiridor imparcial, neutro absolutamente. $\mathrm{O}$ caçador de meu próprio aspecto formal, movido por curiosidade, quando não impessoal, desinteressada; para não dizer o urgir científico. Levei 
meses. (ROSA, 1969, p. 73-74)

Fazendo o inverso de Jacobina, que só pode se ver completo no espelho vestindo a farda do "senhor alferes", o narradorinvestigador de Rosa deseja livrar-se das camadas externas. Segundo ele próprio, sua necessidade era "transverbar o embuço, a travisagem daquela máscara, a fito de devassar o núcleo dessa nebulosa - a minha forma vera" (ROSA, 1969, p. 74). Se, para o narrador machadiano, o homem só se completa na confluência das almas externa e interna, metafisicamente falando, como uma laranja, o narrador rosiano vai como que se livrando das camadas exteriores que o envolvem como se fosse, existencialmente falando, uma cebola. Era preciso, pois, que ele mudasse a forma de se ver, tentando não enxergar aquilo que já conhecia em si: "(...) era principalmente no modus de focar, na visão parcialmente alheada que eu tinha de agilitar-me: olhar não-vendo. Sem ver o que, em "meu" rosto, não passava de um reliquat bestial" (ROSA, 1969, p. 75), afirmou. Como resultado, o que se viu no espelho foi o nada ver:

Não vi nada, só o campo, liso, às vácuas, aberto como o sol, água limpíssima, à dispersão da luz, tapadamente tudo. Eu não tinha formas, rosto? Apalpei-me, em muito. Mas, o invisto. O ficto. O sem evidência física. Eu era o transparente contemplador? (ROSA, 1969, p. 76).

Sendo assim, diante da terrível possibilidade de que não haveria em si uma existência central, pessoal, autônoma, de modo que o que se lhe fingia de um suposto eu "não era mais que, sobre a persistência animal, um pouco de herança, de soltos instintos, energia passional estranha, um entrecruzar-se de influências e de tudo o mais que na impermanência se define" (ROSA, 1969, p. 77), o narrador conclui que "Seríamos não mais do que crianças - o espírito do viver não passando de ímpetos espasmódicos, relampejados entre miragens: a esperança e a memória" (ROSA, 1969, p. 77). Talvez por isso, o rosto que finalmente se materializava como imagem-reflexo do eu no espelho seja justamente o de uma criança: "rostinho de menino, de menos-que-menino, só. Só” (ROSA, 1969, p. 78).

No caminho de compreender ou tentar, por meio do discurso poético, promover sua busca por um sentido para a existência, o narrador trava uma batalha contra o espelho, que, por sua vez, reflete metonimicamente outras imagens já consagradas pela sua poética de Guimarães Rosa. O sentido da investigação 
que se traduz no redimensionamento do olhar diante do espelho-metáfora dialoga com a empreitada a que se lança o pai na busca do impossível em "A terceira margem do Rio", ou no caminho narrativo percorrido por Riobaldo entre as palavras que iniciam e terminam o romance: "Nonada" e "Travessia". Segundo Ronaldes de Melo e Souza (1978),

(...) a máscara ou disfarce externo do rosto deve ser eliminado para que possa emergir o verdadeiro rosto do homem. Nesta perspectiva, "O espelho", de Primeiras estórias, revela a amplitude significativa do projeto moral de Riobaldo. Com efeito, assim como o espelho espelha o rostinho do menino, a narração de Grande sertão: veredas espelha a existência que se descobre e se desvela a si mesma. (SOUZA, 1978, p. 21)

Do mesmo modo que o espelho rosiano reflete uma busca constante que caracteriza o projeto estético do escritor, o espelho machadiano pode também traduzir-se como símbolo metafórico-metonímico de toda a sua obra. Na advertência da primeira edição, de Papéis avulsos (1882), o próprio Machado de Assis explica que, embora o título do livro pareça negar-lhe certa unidade, fazendo "crer que o autor coligiu vários escritos de ordem diversa para o fim de não os perder" (ASSIS, 1989, p. 15), certo é que todos pertencem à mesma família espiritual, refletindo o temperamento estético do autor: "Avulsos são eles, mas não vieram parar aqui como passageiros, que acertam de entrar na mesma hospedaria. São pessoas de uma mesma família, que a obrigação do pai fez sentar à mesa" (ASSIS, 1989, p. 15).

Em síntese, é preciso, portanto, deixar claro que os objetossímbolos espelhos, tanto de Machado de Assis, quanto de Guimarães Rosa, refletem o rosto artístico, o gosto estético e o temperamento poético de seus criadores. No entanto, não podem ser tratados como meras exemplificações de um projeto literário já pronto e acabado, mas como peças importantes e singulares nessa engrenagem. Vistos desse modo, cada um dos textos que compõem o todo de uma obra literária são dela representantes (materializações) e dela criadores (fundamentos). Os estudos literários não podem reduzir, nem mesmo quando tratam apenas da obra de umúnico escritor, todos os seus textos a uma mesma análise externa, sem considerar os elementos que o tornam sempre únicos. A formação do leitor depende do reconhecimento de que cada texto representa ao mesmo tempo um percurso específico dentro da obra, embora 
siga na direção de um mesmo caminho geral. Na estruturação complexa de um grande trabalho artístico, todas as partes falam por si e pelo todo ao mesmo tempo. Por extensão, é isso que faz com que escritores como Machado de Assis e Guimarães Rosa sejam igualmente singulares e universais para a literatura.

\section{MACHADO DE ASSIS, GUIMARÃES ROSA AND THE MIRROR}

\section{ABSTRACT}

More than mere history or storytellers, the great writers are able to create private fictional universes, in which the minimum parts interrelate within an articulated poetic whole. In this sense, all the constituent elements of a plot organically combine in such way that through each one it is possible to see represented the highest discourse intended by the author, although only in complementarity to each other that the entire fabric actually can be materialized. In other words, when a writer elaborates his text, he is at the same time creating a particular - because all in that texture combines in a very specific way - and general universe - to the extent that there is a guiding principle, which will manifest in any other text produced by him. Were it different, only a single artistic object would be sufficient to the writer (and to the reader), as any other would utter exactly what the first would have already revealed. By extension, in the same way a short story can interact with the entire narrative fiction that composes the work of an artist, all of its elements can connect into a kind of metonymic game. Assuming, then, that every literary text is worthy of a singular reading, even though it is obviously inserted in the whole of an aesthetic project, we decided to analyze the imagetic-symbolic aspects, giving special attention to the theme-object chosen by the authors, of homonymous short stories "O Espelho" - by Machado de Assis and by Guimarães Rosa.

Keywords: Machado de Assis. Guimarães Rosa. Mirror. Symbol. Intertextuality. 


\section{REFERÊNCIAS}

ASSIS, Machado de. "Os cegos: tréplica ao Sr. Jq. Sr.", In: MASSA, Jean-Michel (Org.). Dispersos de Machado de Assis. Rio de Janeiro: MEC/ Instituto Nacional do Livro, 1965, p.62.

ASSIS, Machado de. Papéis avulsos. Rio de Janeiro, Belo Horizonte: Livraria Garnier, 1989.

CHEVALIER, Jean \& GHEERBRANT, Alain. Dicionário de símbolos: mitos, sonhos, costumes, gestos, formas, figuras, cores, números. 13.ed. Rio de Janeiro: José Olympio, 1999.

HILÁRIO, Márcio Vinícius do Rosário. A desconstrução do romanesco: uma análise dos primeiros romances de Machado de Assis. Rio de Janeiro: UFRJ / Faculdade de Letras, 2012. Tese de Doutorado em Literatura Brasileira.

HILÁRIO, Márcio Vinícius do Rosário. "Reflexões e divagações diante de 'O espelho'”. In: BASTOS, Dau. (Org.). Jornada discente Machado de Assis: melhores artigos. Rio de Janeiro: UFRJ, Centro de Letras e Artes, Faculdade de Letras, 2009, p.125-9

ROSA, João Guimarães. Primeiras estórias. 5.ed. Rio de Janeiro: José Olympio Editora, 1969.

SOUZA, Ronaldes de Melo. Ficção e verdade: diálogo e caterse em "Grande sertão: veredas". Série Compromisso, n.3. Brasília: Clube de Poesia de Brasília, 1978.

Recebido em: 03/06/2015

Aceito em: 06/05/2016 
LITERATURA E PSICANÁLISE 